\title{
Changes with age in the glycosaminoglycans of human articular cartilage
}

\author{
R. J. ELLIOTT AND D. L. GARDNER
}

From the Department of Histopathology, University of Manchester, Oxford Road, Manchester

SUMMARY Human articular cartilage was obtained post mortem from the lateral femoral condyles of 30 subjects aged from under 1 to 70 years. Cryostat sections taken $0-100 \mu \mathrm{m}$ and $900-100 \mu \mathrm{m}$ deep to the cartilage surface were exhaustively extracted to recover the glycosaminoglycans (GAG). After fractionation by cellulose acetate electrophoresis and enzyme depolymerisation individual GAG were determined by alcian blue $-0.05 \mathrm{M} \mathrm{MgCl}_{2}$ and disaccharide microassay procedures. Changes with age were observed in GAG concentration and in the proportion of individual GAG. Large alterations occurred during the period of skeletal growth (0-16y). At birth GAG formed about $50 \%$ of the dry weight of cartilage, a value that decreased to about $15 \%$ in adult cartilage. Chondroitin sulphates $(\mathrm{ChS})$ formed the principal GAG of articular cartilage and accounted for almost all of the GAG of the infant material. The ChS decreased with age and were partially replaced by keratan sulphate (KS), so that KS eventually comprised $12 \%$ of the GAG. Hyaluronic acid (HA) was identified and was found to increase linearly with age to form $6 \%$ by weight of the cartilage GAG by $60 y$.

Histochemical evidence indicates that the composition of the matrix of human articular cartilage changes during age and in disease (Stockwell and Scott, 1965; Elliott and Gardner 1978a). Biochemical studies of changes in the nature and quantity of cartilage matrix glycosaminoglycans (GAG) during aging have also been obtained in man (Matthews, 1953; Anderson et al., 1964; Rosenberg, et al., 1965; Muir et al., 1970; Stockwell, 1970; Mankin et al., 1971; Hjertquist and Lemperg, 1972; Bjelle et al., 1972; Altman, et al. 1973; Greiling and Baumann, 1973; Stuhlsatz, 1973; Venn, 1978) and in the articular cartilage of other vertebrates (Balazs et al., 1966; Mankin and Lipiello, 1969; Lust et al., 1972; Muthiah and Kuhn, 1973; Lemperg et al., 1974; McDevitt and Muir, 1976). Many of these studies were based on hexosamine assays and the age range, and sample numbers have often been limited.

Stockwell and Scott (1967) segregated cartilage into morphologically defined zonal depths prior to analysis. In this investigation thin cartilage sections were prepared tangetial to the articular surface from human material with an age range from birth to old age. The GAG following extraction were fractionated

Accepted for publication 15 August 1978

Correspondence to Dr R. Elliott, Department of Biochemistry, Medical Biology Centre, Queen's University of Belfast, Belfast BT9. and assayed by recently developed micro-procedures (Elliott and Gardner, 1977, 1978 b, c).

\section{Materials and methods}

Collection of articular cartilage. Whole femurs were obtained from the right leg of 14 male and 16 female cadavers within $30 \mathrm{~h}$ of death (Table 1). Obese subjects and those with a history of prolonged immobilisation, of trauma, or of other diseases related to the hip or knee joints or of metabolic or endocrine abnormality were avoided.

Sampling of cartilage for analysis. Femurs were orientated by Armstrong and Gardner's (1977b) modification of the method described by Kempson et al. (1971) to determine the condylar site at which loading was initially applied in vivo. The marked condyles were removed from the bone shaft with a band saw. The lateral condyle was placed in a woodworker's vice, and a $2.5 \times 1.5 \mathrm{~cm}^{2}$ rectangle of cartilage, with the initial load bearing point in the centre, was delineated with a surgical scalpel. The cartilage was removed from the condyle with a finely honed wood chisel applied at a $45^{\circ}$ angle. Cartilage blocks, trimmed to $20 \times 10 \mathrm{~mm}^{2}$, were placed on the electrically cooled stage of a microtome with the articular cartilage surface face down. The block was trimmed with the microtome knife set at 
Table 1. The glycosaminoglycan composition (as $\mu \mathrm{g} / \mathrm{mg}$ of dry cartilage) of superficial zone (0 to $100 \mu \mathrm{m}$ depth) human articular cartilage samples aged from 0 to 70 years

\begin{tabular}{|c|c|c|c|c|c|c|}
\hline \multirow{2}{*}{$\begin{array}{l}\text { Sample } \\
\text { no. }\end{array}$} & \multirow[t]{2}{*}{ Age $(y)$} & \multicolumn{4}{|c|}{ Electrophoresis $\mathrm{AB}-0.05 \mathrm{M} \mathrm{MgCl} \mathrm{M}_{2}$} & \multirow{2}{*}{$\begin{array}{l}\text { Disaccharide } \\
\text { assay } \\
\text { ChS } \\
(\mu g / m g)\end{array}$} \\
\hline & & $\begin{array}{l}\text { Total } \\
\text { GAG }\end{array}$ & $\begin{array}{l}C h S \\
(\mu \mathrm{g} / m g)\end{array}$ & $K S$ & $H A$ & \\
\hline 1 & 0 & $256 \cdot 79$ & $252 \cdot 17$ & $4 \cdot 62$ & $<0.5$ & $200 \cdot 25$ \\
\hline 2 & $0 \cdot 15$ & $393 \cdot 92$ & $391 \cdot 16$ & $2 \cdot 76$ & $<0.5$ & $126 \cdot 79$ \\
\hline 3 & $0 \cdot 15$ & $416 \cdot 88$ & $394 \cdot 48$ & $22 \cdot 40$ & $<0.5$ & $203 \cdot 20$ \\
\hline 4 & 2 & $312 \cdot 35$ & $294 \cdot 86$ & $17 \cdot 49$ & $<0.5$ & $188 \cdot 14$ \\
\hline 5 & $3 \cdot 5$ & 239.01 & $231 \cdot 18$ & $6 \cdot 17$ & 1.66 & $244 \cdot 83$ \\
\hline 6 & 8 & $176 \cdot 58$ & $161 \cdot 04$ & $15 \cdot 54$ & $<0.5$ & $107 \cdot 11$ \\
\hline 7 & 10 & $130 \cdot 77$ & $116 \cdot 65$ & $14 \cdot 12$ & $<0.5$ & $122 \cdot 35$ \\
\hline 8 & 12 & $82 \cdot 20$ & $74 \cdot 64$ & $7 \cdot 56$ & $<0.5$ & 90.03 \\
\hline 9 & 12 & $119 \cdot 33$ & $100 \cdot 25$ & $17 \cdot 14$ & $1 \cdot 94$ & $116 \cdot 21$ \\
\hline 10 & 13 & $130 \cdot 72$ & $108 \cdot 79$ & $19 \cdot 65$ & $2 \cdot 28$ & $126 \cdot 29$ \\
\hline 11 & 18 & $126 \cdot 30$ & $95 \cdot 59$ & $26 \cdot 69$ & $1 \cdot 02$ & 95.04 \\
\hline 12 & 18 & $137 \cdot 79$ & 97.49 & $37 \cdot 73$ & $2 \cdot 57$ & 99.67 \\
\hline 13 & 20 & $125 \cdot 21$ & $100 \cdot 03$ & $23 \cdot 20$ & $1 \cdot 98$ & $74 \cdot 59$ \\
\hline 14 & 20 & $134 \cdot 16$ & $119 \cdot 46$ & $12 \cdot 39$ & $2 \cdot 31$ & $111 \cdot 23$ \\
\hline 15 & 22 & 137.06 & $115 \cdot 86$ & $19 \cdot 17$ & 2.03 & $116 \cdot 26$ \\
\hline 16 & 26 & 96.07 & $80 \cdot 58$ & $10 \cdot 57$ & $4 \cdot 92$ & $85 \cdot 98$ \\
\hline 17 & 32 & $105 \cdot 25$ & $72 \cdot 91$ & $30 \cdot 36$ & $1 \cdot 98$ & $73 \cdot 88$ \\
\hline 18 & 36 & $107 \cdot 51$ & $70 \cdot 98$ & $34 \cdot 18$ & $2 \cdot 35$ & $110 \cdot 06$ \\
\hline 19 & 37 & $165 \cdot 13$ & $140 \cdot 51$ & 20.99 & $3 \cdot 63$ & $136 \cdot 64$ \\
\hline 20 & 39 & $126 \cdot 62$ & $102 \cdot 24$ & $18 \cdot 47$ & $5 \cdot 91$ & $88 \cdot 21$ \\
\hline 21 & 43 & $78 \cdot 28$ & $61 \cdot 70$ & 9.63 & 6.95 & $57 \cdot 84$ \\
\hline 22 & 43 & $105 \cdot 89$ & $82 \cdot 39$ & $16 \cdot 16$ & $7 \cdot 34$ & $80 \cdot 18$ \\
\hline 23 & 46 & $76 \cdot 90$ & $58 \cdot 28$ & 14.94 & $3 \cdot 68$ & $68 \cdot 47$ \\
\hline 24 & 47 & $91 \cdot 82$ & 63.02 & $25 \cdot 24$ & $3 \cdot 56$ & $68 \cdot 58$ \\
\hline 25 & 51 & $68 \cdot 91$ & 47.05 & $17 \cdot 85$ & $4 \cdot 01$ & 58.08 \\
\hline 26 & 53 & $141 \cdot 34$ & $110 \cdot 21$ & $28 \cdot 77$ & $2 \cdot 36$ & $121 \cdot 76$ \\
\hline 27 & 55 & $196 \cdot 46$ & $145 \cdot 61$ & $47 \cdot 76$ & 3.09 & $191 \cdot 67$ \\
\hline 28 & 56 & $164 \cdot 21$ & $134 \cdot 64$ & $21 \cdot 56$ & $8 \cdot 01$ & $116 \cdot 50$ \\
\hline 29 & 68 & $74 \cdot 26$ & $58 \cdot 08$ & $11 \cdot 39$ & $4 \cdot 79$ & $35 \cdot 63$ \\
\hline 30 & 70 & $83 \cdot 30$ & 69.64 & $10 \cdot 41$ & $3 \cdot 25$ & $75 \cdot 23$ \\
\hline
\end{tabular}

The extracted GAGs were fractionated by cellulose acetate electro-

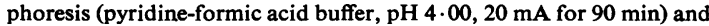
stained with $0.2 \%(\mathrm{w} / \mathrm{v})$ alcian blue in $50 \mathrm{mM}$ acetate buffer, $\mathrm{pH}$ 5.8 , containing $0.05 \mathrm{M} \mathrm{MgCl}$ for $60 \mathrm{~min}$. The characteristically stained band of hyaluronic acid and the broad band containing chondroitin sulphates (ChS) and keratan sulphate (KS) (Fig. 2) were measured by densitometry. After removal of $\mathrm{ChS}$ by chondroitin $\mathrm{ABC}$ lyase (EC 4.2.2.4) the single band of KS was determined. The ChS concentration was obtained (1) from the difference before and after treatment with chondroitin ABClyase and (2) with the acid periodatethiobarbituric acid assay (Elliott and Gardner, 1977).

$20 \mu \mathrm{m}$ advancement until a planar surface was obtained. The cartilage block was thawed and then reversed with the surface layer of cartilage now uppermost, refrozen, and $100 \mu \mathrm{m}$ serial sections made. The first section ( 0 to $100 \mu \mathrm{m}$ deep to the surface) and the tenth section (900 to $1000 \mu \mathrm{m}$ deep to the surface) were freeze-dried and the dry weights determined.

Glycosaminoglycan reference material. Standard GAG were obtained from several commercial suppliers; they frequently contained contaminating material, including other GAG. The GAG preparations were therefore purified by cellulose acetate electrophoresis fractionation (Elliott and Gardner, 1978c). Keratan sulphate (KS II type) was prepared from human nucleus pulposus obtained post mortem from cadavers aged in excess of $70 \mathrm{y}$.
The KS was extracted by the procedure describeç. below. ChS was removed by treatment with: chondroitin ABC lyase EC 4.2.2.4 (Seikagakup? Kogyo Co., Tokyo, Japan). Protein was removeф with papain (Sigma Chemical Co., London)온 Analytical grade chemicals were used when availables

Extraction of cartilage glycosaminoglycans. Eack dry $100 \mu \mathrm{m}$ cartilage section was broken into smald fragments and transferred to a $5 \times 1 \mathrm{~cm}^{2}$ test-tube and $2.5 \mathrm{ml}$ of precooled solvent $\left(0.2 \mathrm{M} \mathrm{NH}_{4} \mathrm{Cl}\right.$ aP $\mathrm{pH} \mathrm{7.00)}$ added. in a solvent-to-cartilage ratio of 500:1. Capped tubes were placed on a slow speec. rotary mixer, transferred to a $4^{\circ} \mathrm{C}$ cold room extracted by continuous rotary mixing for $18 \mathrm{~h}$, and then centrifuged at 5000 r.p.m., at $4^{\circ} \mathrm{C}$ for $30 \mathrm{~min}^{\circ}$ To the cartilage residue a further $2.5 \mathrm{ml}$ of cold solvent was added and the extraction repeated for $21 \mathrm{~h}$. To the supernates and residue $2.5 \mathrm{ml}$ o? precooled $0.5 \mathrm{~N} \mathrm{Na0H}$ was added and held at $4^{\circ} \mathrm{C}$ for $4 \mathrm{~h}$. The residue was centrifuged. All supernates were adjusted to $\mathrm{pH} \mathrm{7.00} \mathrm{with} \mathrm{acetic} \mathrm{acid} \mathrm{an} \Phi$ transferred to a $250 \mathrm{ml}$ glass-stoppered reagent bottle containing $80 \mathrm{ml}$ ethanol and $12 \mathrm{ml} 40 \%$ w/v sodium acetate, $\mathrm{pH} 7 \cdot 6$. The residue was extracted with a further $2.5 \mathrm{ml}$ of $0.5 \mathrm{~N} \mathrm{NaOH}$ for $4 \mathrm{~h}$ and the neutralised supernate (fourth extract) added to the pooled extracts. The cartilage extract in acetates saturated ethanol was held at $4^{\circ} \mathrm{C}$ for 5 days before recovering the finely dispersed GAG precipitate bo centrifugation at 15000 r.p.m. at $4^{\circ} \mathrm{C}$ for $30 \mathrm{~min} ?$ The GAG deposit was taken up into $2.0 \mathrm{ml}$ of $5 \%$ $(w / v)$ sodium acetate.

Aliquots of cartilage residues remaining after sal and alkali extraction were added to concentrate sulphuric acid and examined for the presence ox uronic acid by heating with carbazole. The bulk of each residue was washed with $0.9 \%$ w/v NaCl an suspended in citrate buffer, $\mathrm{pH} 4 \cdot 2$. Drops of the buffered suspensions were placed on carbon 3 coated EM grids and stained with $0.5 \% \mathrm{w} / \mathrm{v}$ urany acetate for $10 \mathrm{~s}$. The grids were examined for the presence of noncollagenous material at magnificae tions up to $\times 190000$ in an AEI Model 801 electroi microscope at an operating voltage of $60 \mathrm{kV}$.

Fractionation and measurement of glycosaminos glycans. Total GAG, the HA, and the combinea ChS-KS components of the extract samples after fractionation by cellulose acetate electrophoresis were determined after reaction with $0.2 \% \mathrm{w} / \mathrm{b}$ alcian blue in $0.05 \mathrm{M} \mathrm{MgCl}_{2}$ at pH 5.80 (Elliott an Gardner, 1978c). The KS fraction was determined after removal of the $\mathrm{ChS}$ with chondroitin $\mathrm{ABC}$ lyase. The quantity of $\mathrm{ChS}$ was calculated from th difference before and after treatment with chondroitin $\mathrm{ABC}$ lyase and as sulphate\& disaccharides by the periodate-thiobarbituric aciof 


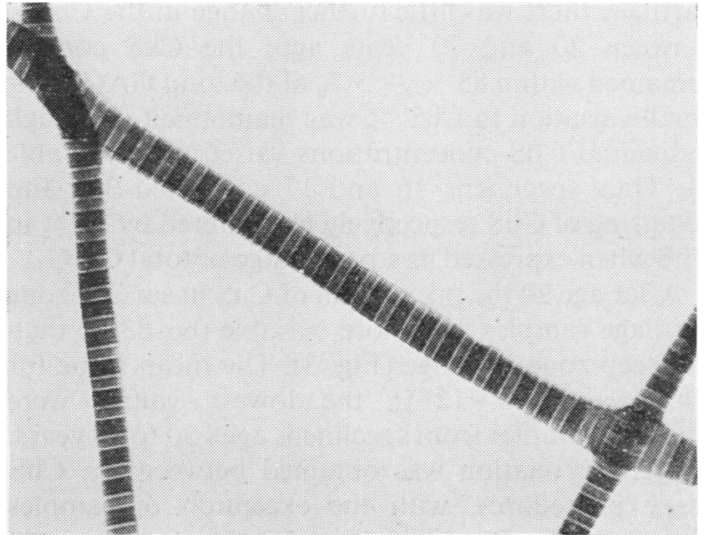

Fig. 1 Electron micrograph of the cartilage residue remaining after the 4-stage extraction procedure for the recovery of glycosaminoglycans $(\times 40000)$

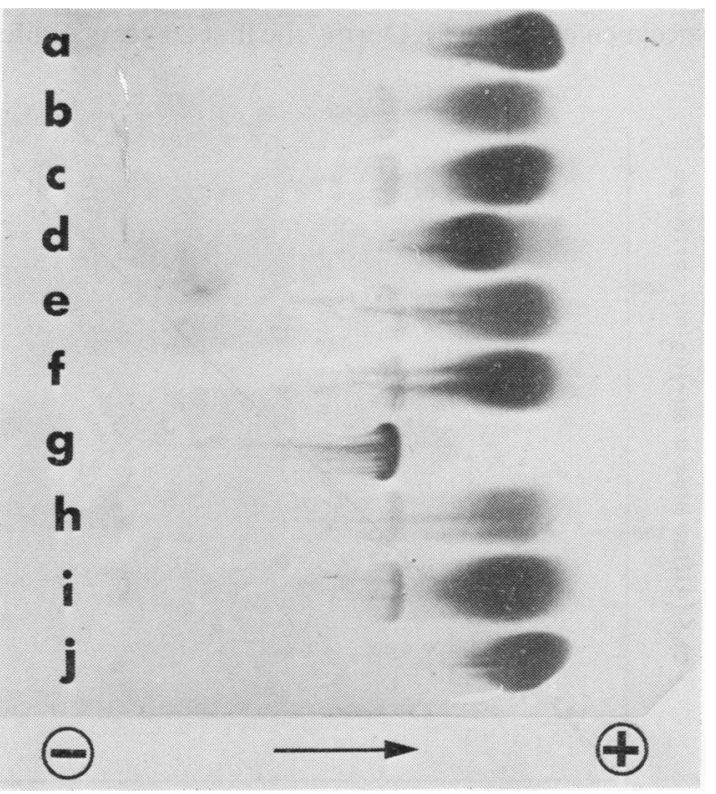

Fig. 2 Cellulose acetate electrophoretic separation of hyaluronic acid from other articular cartilage glycosaminoglycans. Large sample aliquots were used to produce visually discernible articular cartilage hyaluronic acid. Sample (a) is a chondroitin-6-sulphate standard; (b) human articular cartilage, 0-100 $\mathrm{\mu m}$ depth and (c) at 900-100 $\mu \mathrm{m}$ depth; (d) keratan sulphate standard (impure); (e) human articular cartilage, 0-100 $\mu \mathrm{m}$ depth and $(f)$ at 900-1000 $\mu \mathrm{m}$ depth; $(g)$ hyaluronic acid standard; $(h)$ human articular cartilage, 0-100 $\mu \mathrm{m}$ depth, and (i) at 900-1000 $\mu \mathrm{m}$ depth; $(j)$ chondroitin-4-sulphate standard. The detection agent was $0 \cdot 2 \%(\mathrm{w} / \mathrm{v})$ alcian blue-0.05 $\mathrm{M} \mathrm{MgCl}_{2}$ at pH 5.8 for $60 \mathrm{~min}$. Unbound dye was removed in $80 \%(\mathrm{v} / \mathrm{v})$ ethanol reaction (Elliott and Gardner, 1977). Purified GAG standards were included with each assay.

Histochemical examination of articular cartilage. Frozen unfixed $5 \mu \mathrm{m}$ thick cartilage sections were prepared from each sample block and stained with alcian blue (AB) $-0.2 \mathrm{M} \mathrm{MgC1} 1_{2}$ for $8 \mathrm{~h}$. These sections provided supplementary information of cartilage structure and GAG distribution.

\section{Results}

The 4-stage extraction process quantitatively recovered the GAG from infant and adult cartilage samples. Uronic acid was not detected in the insoluble residue and electron microscopic examination indicated the absence of non-collagenous material (Fig. 1). A small quantity of hydroxyproline was present in the extracts, most of which was in fine suspension as it could be removed by centrifugation.

The GAG composition of the 60 samples of articular cartilage obtained from 30 femoral condyles in the age range 0 to 70 years are tabulated in Tables 1 and 2. The results, in chronological order, are expressed as $\mu \mathrm{g} \mathrm{GAG} / \mathrm{mg}$ dry cartilage. The GAG

Table 2 The glycosaminoglycan composition (as $\mu \mathrm{g} / \mathrm{mg}$ of dry cartilage) of deep zone (900 to $1000 \mu \mathrm{m}$ depth from surface) human articular cartilage samples aged from 0 to 70 years

\begin{tabular}{|c|c|c|c|c|c|c|}
\hline \multirow{2}{*}{$\begin{array}{l}\text { Sample } \\
\text { no. }\end{array}$} & \multirow[t]{2}{*}{ Age $(y)$} & \multicolumn{4}{|c|}{ Electrophoresis $A B-0.05 M \mathrm{MgCl}_{2}$} & \multirow{2}{*}{$\begin{array}{l}\text { Disaccharide } \\
\text { assay } \\
\text { ChS } \\
(\mu g / m g)\end{array}$} \\
\hline & & $\begin{array}{l}\text { Total } \\
\text { GAG }\end{array}$ & $\begin{array}{l}C h S \\
(\mu g / m g)\end{array}$ & $K S$ & $H A$ & \\
\hline 1 & 0 & $522 \cdot 22$ & $502 \cdot 33$ & $20 \cdot 89$ & $<0.5$ & $473 \cdot 69$ \\
\hline 2 & $0 \cdot 15$ & $476 \cdot 24$ & $468 \cdot 52$ & $5 \cdot 69$ & 2.03 & $444 \cdot 15$ \\
\hline 3 & $0 \cdot 15$ & $494 \cdot 67$ & $460 \cdot 63$ & $34 \cdot 04$ & $<0.5$ & $477 \cdot 89$ \\
\hline 4 & 2 & $281 \cdot 57$ & $259 \cdot 32$ & $22 \cdot 25$ & $<0.5$ & $244 \cdot 51$ \\
\hline 5 & $3 \cdot 5$ & $174 \cdot 52$ & $167 \cdot 36$ & $7 \cdot 16$ & $<0.5$ & $95 \cdot 11$ \\
\hline 6 & 8 & $150 \cdot 67$ & $145 \cdot 85$ & $4 \cdot 82$ & $<0.5$ & $79 \cdot 71$ \\
\hline 7 & 10 & 52.07 & $45 \cdot 14$ & 6.93 & $<0.5$ & $45 \cdot 11$ \\
\hline 8 & 12 & $108 \cdot 26$ & 96.02 & $11 \cdot 27$ & 0.97 & 64.99 \\
\hline 9 & 12 & $186 \cdot 92$ & $171 \cdot 90$ & $12 \cdot 15$ & $2 \cdot 87$ & $184 \cdot 70$ \\
\hline 10 & 13 & $88 \cdot 18$ & $81 \cdot 66$ & $5 \cdot 31$ & $1 \cdot 21$ & $92 \cdot 83$ \\
\hline 11 & 18 & $101 \cdot 29$ & 92.65 & $7 \cdot 30$ & $1 \cdot 34$ & $75 \cdot 27$ \\
\hline 12 & 18 & $226 \cdot 95$ & $199 \cdot 54$ & $21 \cdot 93$ & $5 \cdot 48$ & 212.04 \\
\hline 13 & 20 & 68.99 & $56 \cdot 62$ & 10.79 & $1 \cdot 58$ & 46.42 \\
\hline 14 & 20 & $177 \cdot 91$ & $158 \cdot 64$ & $13 \cdot 23$ & 6.04 & $164 \cdot 02$ \\
\hline 15 & 22 & $196 \cdot 30$ & $171 \cdot 28$ & $19 \cdot 24$ & $5 \cdot 78$ & $207 \cdot 45$ \\
\hline 16 & 26 & $454 \cdot 46$ & $366 \cdot 60$ & $58 \cdot 69$ & $29 \cdot 17$ & 359.42 \\
\hline 17 & 32 & $83 \cdot 85$ & $73 \cdot 02$ & 6.02 & $4 \cdot 81$ & $70 \cdot 41$ \\
\hline 18 & 36 & $238 \cdot 88$ & $206 \cdot 78$ & $21 \cdot 71$ & $10 \cdot 39$ & $245 \cdot 70$ \\
\hline 19 & 37 & $180 \cdot 96$ & 149.04 & $19 \cdot 75$ & $12 \cdot 17$ & $159 \cdot 35$ \\
\hline 20 & 39 & $169 \cdot 25$ & $137 \cdot 64$ & $22 \cdot 59$ & 9.02 & $115 \cdot 61$ \\
\hline 21 & 43 & $122 \cdot 35$ & $106 \cdot 87$ & 9.93 & $5 \cdot 55$ & $100 \cdot 53$ \\
\hline 22 & 43 & $127 \cdot 62$ & $104 \cdot 63$ & $18 \cdot 18$ & $4 \cdot 81$ & $103 \cdot 37$ \\
\hline 23 & 46 & $208 \cdot 69$ & $176 \cdot 82$ & $24 \cdot 80$ & 7.07 & 207.62 \\
\hline 24 & 47 & $105 \cdot 61$ & $87 \cdot 19$ & $11 \cdot 11$ & $7 \cdot 31$ & 96.99 \\
\hline 25 & 51 & $181 \cdot 25$ & $155 \cdot 59$ & $16 \cdot 71$ & 8.95 & $178 \cdot 20$ \\
\hline 26 & 53 & $187 \cdot 79$ & $157 \cdot 61$ & 19.48 & $10 \cdot 70$ & $150 \cdot 80$ \\
\hline 27 & 55 & $195 \cdot 61$ & 155.47 & $31 \cdot 62$ & $8 \cdot 52$ & $195 \cdot 44$ \\
\hline 28 & 56 & $147 \cdot 66$ & $128 \cdot 26$ & $14 \cdot 25$ & $5 \cdot 15$ & $125 \cdot 03$ \\
\hline 29 & 68 & $137 \cdot 52$ & $116 \cdot 13$ & $18 \cdot 59$ & $2 \cdot 80$ & $113 \cdot 45$ \\
\hline 30 & 70 & $120 \cdot 21$ & $95 \cdot 58$ & 12.06 & $12 \cdot 57$ & 90.69 \\
\hline
\end{tabular}

For the method of fractionation and assay see Table 1. 
content of articular cartilage was highest at birth, deep zone cartilage containing about twice the GAG concentration of surface zone cartilage. The concentration of GAG in both surface and deep cartilage zones declined rapidly during the first 4 years of life. The ChS was found to be the principle GAG with KS forming the second largest component. The presence of HA in human articular cartilage was identified after separation from $\mathrm{ChS}$ and KS (Fig. 2).

\section{CHONDROITIN SULPHATE COMPOSITION}

The ChS values (Tables 1 and 2) were expressed as a percentage of the total GAG concentration and plotted against specimen age (Fig. 3). At birth $\mathrm{ChS}$ accounted for almost all the GAG found in articular cartilage. The $\mathrm{ChS}$ as a percentage of cartilage GAG decreased during the first 20 years of life. At growth maturity ChS represented about $85 \%$ of the total GAG composition. In deep zone (900 to $1000 \mu \mathrm{m})$

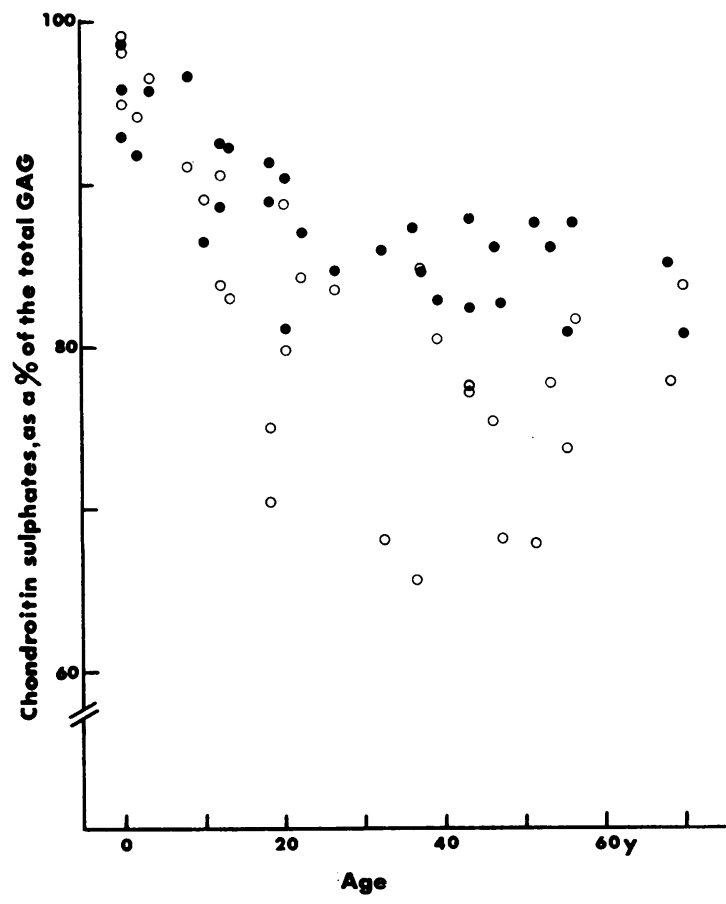

Fig. 3 Age distribution of chondroitin sulphates; from samples obtained at a depth of (O) 0 to $100 \mu \mathrm{m}$ and (O) 900 to 1000 um from the cartilage surface. Chondroitin sulphates (ChS) were measured following electrophoretic separation and staining with alcian blue-0.05M MgCl2. The ChS is expressed as a percentage of the total glycosaminoglycan concentration of the sample (Table 1) cartilage there was little further change in the $\mathrm{ChS} \% \frac{\mathrm{O}}{\mathrm{c}}$ between 20 and 70 years age; the ChS content remained within $85 \% \pm 5 \%$ of the total GAG. This $\stackrel{\vec{\rho}}{?}$ small variation in $\mathrm{ChS} \%$ was maintained, althougho individual $\mathrm{ChS}$ concentrations varied widely (Table 흠 1). Thus specimens 16 and 17 contained 366 and $\frac{\bar{p}}{7}$ $73 \mu \mathrm{g} / \mathrm{mg}$ of $\mathrm{ChS}$ respectively but differed by $<2 \%$ in $\stackrel{\varnothing}{\unrhd}$ $\mathrm{ChS}$ when expressed as a percentage of total GAG.

After age 20 the proportion of $\mathrm{ChS}$ in surface zone cartilage samples was more variable (66-85\%) than the deep zone cartilage (Fig. 3). The mean value for $\vec{\omega}$ ChS was $78 \pm 12 \%$; the lowest values were found in samples from specimens aged 30 to 50 years. A high correlation was obtained between the $\mathrm{ChS}$ assay procedures, with the exception of samples from $0-2$ y aged cartilage (Fig. 4).

\section{KERATAN SULPHATE COMPOSITION}

The KS values in Tables 1 and 2 were expressed as a percentage of total GAG and plotted against specimen age (Fig. 5) .During the first 20 years of lifece

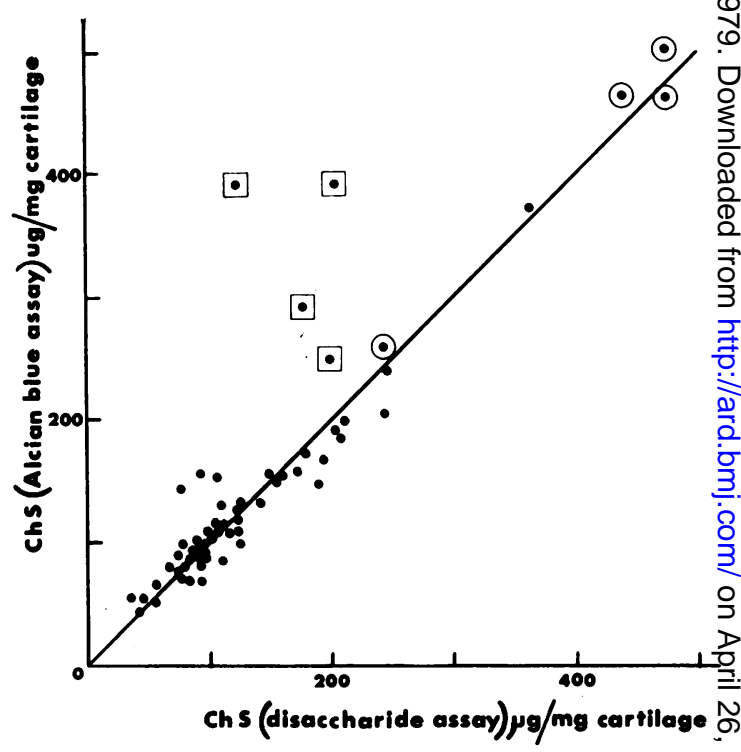

Fig. 4 Comparison of the methods used to measure the chondroitin sulphates of articular cartilage. Chondroitin sulphates were determined using (a) alcian blue- $0.05 \mathrm{M} \mathrm{MgCl}$ before and after treatment with chondroitin $A B C$ lyase $(0.1$ unit enzyme in

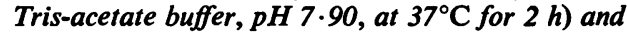
(b) by acid periodate oxidation $(0.02 \mathrm{M} \mathrm{Na} \mathrm{OO}$ at pH 2.20 for 60 min at $37^{\circ} \mathrm{C}$ ) and colour formation with thiobarbituric acid $\left(0.3 \% \mathrm{w} / \mathrm{v}\right.$ at $100^{\circ} \mathrm{C}$ for $15 \mathrm{~min}$ ) Q samples 0 to $2 y, 0$ to $100 \mu \mathrm{m}$ cartilage depth; o samples 0 to $2 y, 900$ to 1000 rm cartilage depth; samples 3.5 to $70 y$ at both cartilage depths 


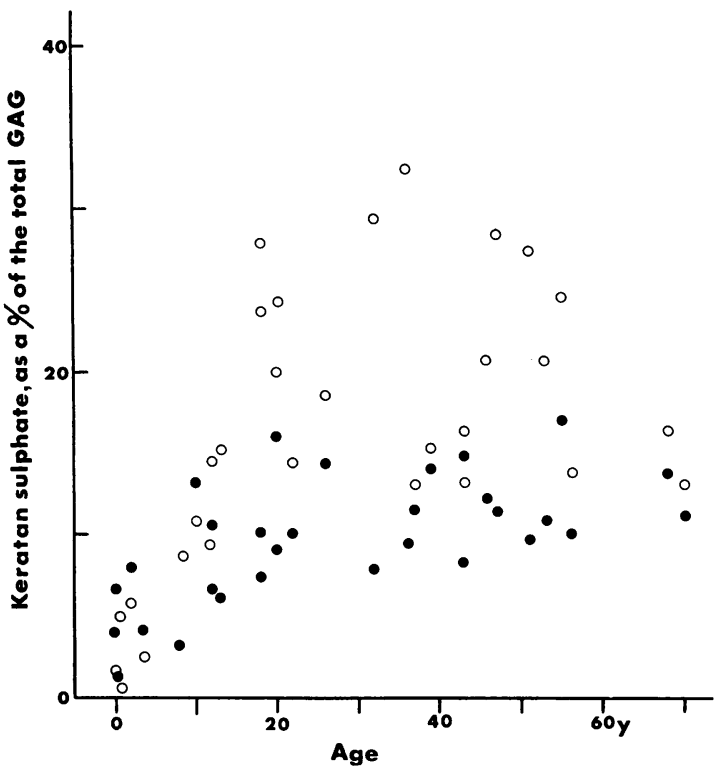

Fig. 5 Age-distribution of keratan sulphate; from samples obtained at a depth of (O) 0 to $100 \mu \mathrm{m}$ and (O) 900 to $1000 \mu \mathrm{m}$ from the cartilage surface. Cartilage $C h S$ and $H A$ were removed by enzymatic depolymerisation (chondroitin ABC lyase, pH 7.90 at $37^{\circ} \mathrm{C}$ for $2 \mathrm{~h}$ ). Keratan sulphate $(K S)$ isolated by cellulose acetate electrophoresis was determined by densitometry of the $K S-A B$ complex. The $K S$ is expressed as a percentage of the total glycosaminoglycan concentration of the sample (Table 1)

KS gradually increased to reach about $15 \%$ of the total GAG. This increase in part complemented the decrease in $\mathrm{ChS}$ during the growth period. As was observed with $\mathrm{ChS}$, the proportion of $\mathrm{KS}$ in deep zone cartilage did not vary widely $(12 \% \pm 4 \%$ from 20 to 70 years). The relatively larger quantity of KS in the surface zone cartilage, however, showed greater percentage variation. In several samples from specimens aged 20 to 50 years the KS formed $20-30 \%$ of the total GAG.

\section{HYALURONIC ACID COMPOSITION}

Hyaluronic acid did not exceed $1 \%$ of the total GAG until after completion of skeletal growth (Fig. 6). The HA as a percentage increased linearly with age; by 60 years it formed $6 \%$ of the total GAG. The HA occurred in both surface and deep zone cartilage (Fig. 2). Deep zone samples contained relatively more HA than surface zone samples (Tables 1 and 2). Expressed as \% of total GAG, the proportion of HA in deep zone samples was, however, similar to that in the surface zone (Fig. 6).

In adult articular cartilage the GAG ratio of $\mathrm{HA}$ :

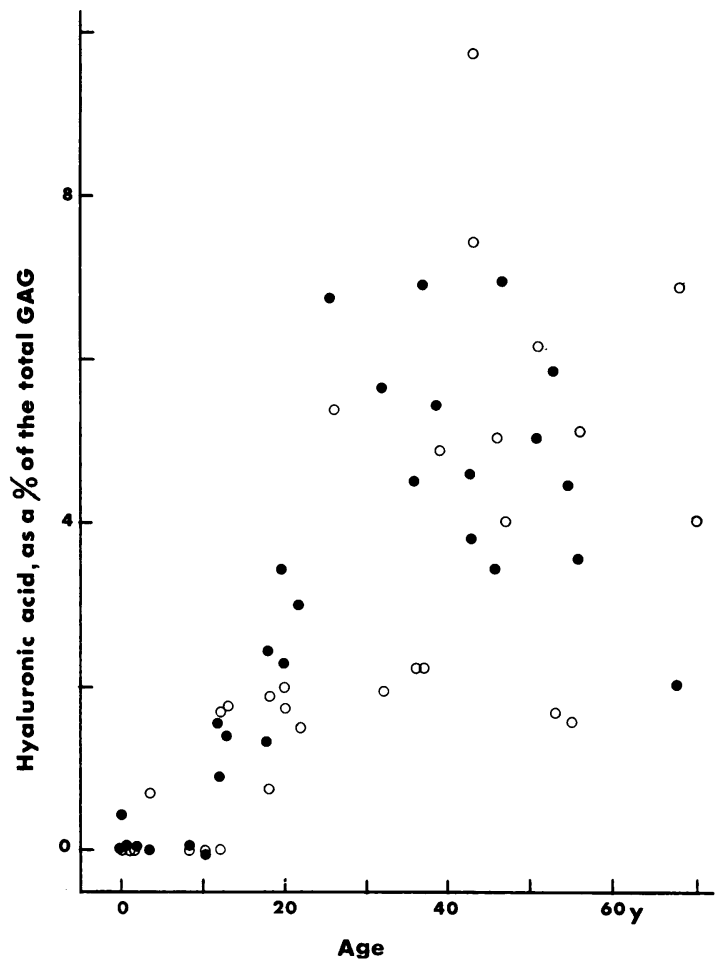

Fig. 6 Age distribution of hyaluronic acid; from samples obtained at a depth of (O) 0 to $100 \mu \mathrm{m}$ and (O) to 900 to $1000 \mu \mathrm{m}$ from the cartilage surface. Articular cartilage hyaluronic acid isolated and detected as shown in Fig. 1 was determined by densitometry and expressed as a percentage of the total glycosaminoglycan concentration of the sample (Table 1)

ChS: KS, by weight, was $3: 85: 12$. After conversion to $\mu$ moles, the HA : ChS : KS ratio became $0 \cdot 1$ : $73: 27$.

\section{Discussion}

This study has demonstrated that articular cartilage chondrocytes express $\mathrm{ChS}$ in the first few days of human postnatal life. After about 25 months analyses confirmed that $\mathrm{KS}$ and $\mathrm{HA}$ were also present in the cartilage matrix (Tables 1 and 2). The total content of GAG in cartilage declines rapidly after birth, a decrease attributable to diminished $\mathrm{ChS}$, for although KS and HA increase in amount their smaller absolute quantities do not compensate in full for the loss of ChS. When body growth was complete, the surface zone cartilage contained about $15 \%$ (dry weight) as GAG, which decreased during aging to reach about $7 \%$ by 70 years. 
During aging (20-70 y) the superficial zone of adult cartilage accumulated a higher percentage of KS than deep zone cartilage (Fig. 5). Three explanations are suggested for this observation: (1) that the increase in KS is due to faster turnover of surface zone cartilage GAG caused by wear during the mechanical functioning of the synovial joint; (2) that chondrocyte differentiation and/or feedback control of matrix synthesis is zone dependent, with chondrocytes in the surface cartilage zone synthesising more KS than chondrocytes in the deeper zones. The partial replacement of $\mathrm{ChS}$ by $\mathrm{KS}$ could significantly alter the structure and size of proteoglycans and decrease cartilage hydration. Alternatively, (3) KS may accumulate coincidentially because of enzymes present in the matrix that degrade $\mathrm{ChS}$ and for which KS is not a substrate.

The optimum HA concentrations for the aggregation of PG monomers occurs with HA : PG weight ratios between 1:100 and 10:100. Ratios of $<1: 100$ and $>10: 100$ reduce PG aggregation (Hardingham and Muir, 1974). In this study the ratio of HA to total GAG ( $\equiv 90 \%$ of the weight of PG) ranged from $<1: 100$ to $11: 100$ (Fig. 6). During the first decade of life little HA could be detected, implying minimal PG aggregation, a hypothesis that could be tested by assessing the ease of PG extraction from infant cartilage. After $10 \mathrm{y}$ the HA content increased to reach $2 \%$ by $20 \mathrm{y}, 4 \%$ by $40 \mathrm{y}$, and $6 \%$ by $60 \mathrm{y}$. Thus, during the latter half of maturation and the entire aging period covered in this survey the HA: GAG ratio was within the optimum range for PG aggregation as defined by Hardingham and Muir (1974).

The results reported in this paper were derived from material selected on the basis of hospital admission, age, and anatomical location; the samples were further differentiated by cartilage depth. The selection procedures may have failed to reveal subtle pathological changes in cartilage structure not related to aging. Nevertheless, gross abnormalities, including the disorders of overt osteoarthrosis, were minimised. On this basis it is considered that changes with age in the patterns of articular cartilage GAG can be identified; these age-associated changes are characteristic for the periods of infancy, growth, and maturation. During adult life a further sequence of changing GAG synthesis can be recognised. Whether any or all of these alterations in cartilage GAG composition are caused by the attributes of senescence, in which sense they could be said to be pathological, is unknown. Aging and degenerative disease may of course be interrelated, but this causal association is not yet known to be the basis of most instances of osteoarthrosis. It remains possible that the alterations in molecular composition of articular cartilage described in this paper are coincidental features of the aging process. Since, however, the molecular composition of articular:cartilage and in particular the quality and quantity? of the proteoglycans, determine its response to physical stress and its reaction to physiologically induced deformation, it is apparent that the pro $\frac{\bar{D}}{\vec{D}}$ gressive alterations in cartilage composition demon- $\frac{\pi}{2}$ strated here offer part, if not the entire, explanatione for the changed capacity of aging cartilage to act efficiently as a load bearing surface (Armstrong and Gardner 1977a). To obtain more direct evidence for $\vec{\omega}$ this proposal, and in particular proof that the proteoglycans themselves change with age, must be the object of further investigations that are now inci progress.

\section{References}

Altman, R. D., Pita, J. C., and Howell, D. S. (1973). Degrada-음 tion of proteoglycans in human osteoarthritic cartilage.Arthritis and Rhuematism, 16, 179-185.

Anderson, C. E., Ludowieg, J., Harper, H. A., and Engleman E. P. (1964). The composition of the organic component of human articular cartilage. Journal of Bone and Joint Surgery, 46A, 1176-1183.

Armstrong, C. G., and Gardner, D. L. (1977a). Alteration with age in compliance of human femoral-head cartilage: Lancet, 1, 1103-1104.

Armstrong, C. G., and Gardner, D. L. (1977b). Thickness and distribution of human femoral head articular cartilage. Annals of the Rheumatic Diseases, 36, 407-412.

Balazs, E. A., Bloom, G. D., and Swann, D. A. (1966). Fineڤ structure and glycosaminoglycan content of the surface layer of articular cartilage. Federation Proceedings, 25, $1813-1816$

Bjelle, A. O., Antonopoulas, C. A., Engfeldt, B., and Hjertquist, S. O. (1972). Fractionation of the glycosaminoglycans of human articular cartilage on ecteola cellulose in ageing and in osteoarthrosis. Calcified Tissue Research, 8, 237-246.

Elliott, R. J., and Gardner, D. L. (1977). The micro-assay of the disaccharide isomers of chondroitin sulphate. Biochimica et Biophysica Acta, 498, 349-354.

Elliott, R. J., and Gardner, D. L. (1978a). Quantitative histochemical examination of human articular cartilage $₹$ during ageing. Clinical Science and Molecular Medicine, 55, $\mathrm{O}$ $14-15$.

Elliott, R. J., and Gardner, D. L. (1978b). The 0-, 4- and 6- sulphated disaccharides of chondroitin sulphates: their electrophoretic separation and detection with p-ansidine. $\bar{N}$ Biochemical Society Transactions, 6, 768-769.

Elliott, R. J., and Gardner, D. L. (1978c). Electrophoretic and enzymatic fractionation of articular cartilage glycosaminoglycans. Submitted for publication.

Greiling, H., and Baumann, G. (1973.) Age dependent changes of non-sulphated disaccharide groups in the proteoglycans of knee joint cartilage. Connective Tissue and Ageing, p. 160. Edited by H. G. Vogel. Excerpta Medica: Amsterdam.

Hardingham, T. E. ,and Muir, H. (1974). Hyaluronic acid in $T$ cartilage and proteoglycan aggregation. Biochemical $\bar{O}$ Journal, 139, 565-581.

Hjertquist, S. O., and Lemperg, R. (1972). Identification and $\stackrel{\mathscr{Q}}{\overparen{Q}}$ concentration of the glycosaminoglycans of human $\varnothing$ articular cartilage in relation to age and osteoarthritis. Calcified Tissue Research, 10, 223-237. 
Kempson, G. E., Spivey, C. J., Swanson, S. A. V., and Freeman, M. A. R. (1971). Patterns of cartilage stiffness on normal and degenerate human femoral heads. Journal of Biomechanics, 4, 597-603.

Lemperg, R., Larsson, S. E., and Hjertquist, S. O. (1974). The glycosaminoglycans of bovine articular cartilage. 1 . Concentration and distribution in different layers in relation to age. Calcified Tissue Research, 15, 237-254.

Lust, G., Pronsky, W., and Sherman, D. M., (1972) Biochemical and ultrastructural observations in normal and degenerative canine articular cartilage. American Journal of Veterinary Research, 33, 2429-2444.

McDevitt, C. A., and Muir, H. (1976). Biochemical changes in the cartilage of the knee in experimental and natural osteoarthritis in the dog. Journal of Bone and Joint Surgery, 58B, 94-101.

Mankin, H. J., and Lipiello, L. (1969). The turnover of adult rabbit articular cartilage. Journal of Bone and Joint Surgery, 51A, 1591-1600.

Mankin, H. J., Dorman, H., Lipiello, L., and Zarins, A. (1971). Biochemical and metabolic abnormalities from osteo-arthritic human hips. 2. Correlation of morphology with biochemical and metabolic data. Journal of Bone and Joint Surgery, 53A, 523-537.

Matthews, B. F. (1953). Composition of articular cartilage in osteoarthritis: Changes in collagen-chondroitin sulphate ratio. British Medical Journal, 2, 660-661.

Muir, H. Bullough, P., and Maroudas, A. (1970). The distribution of collagen in human articular cartilage with some of its physiological implications. Journal of Bone and Joint Surgery, 52B, 554-563.

Muthiah, P., and Kuhn, K. (1973). Studies on proteoglycans obtained from bovine knee joint and ear cartilage: Sequential extraction, fractionation, characterization and their effects on fibril formation, Biochimica et Biophysica Acta, 304, 12-19.

Rosenberg, L., Johnston, B., and Schubert, M. (1965). Proteinpolysaccharides from human articular and costal cartilage. Journal of Clinical Investigation, 44, 1647-1656.

Stockwell, R. A., and Scott, J. E. (1965). Observations on the acid glycosaminoglycan content of the matrix of ageing cartilage. Annals of the Rheumatic Diseases, 24, 341-349.

Stockwell, R. A., and Scott, J. E. (1967). Distribution of acid glycosaminoglycans in human articular cartilage. Nature, 215, 1376-1378.

Stockwell, R. A. (1970). Changes in the acid glycosaminoglycan content of the matrix with ageing. Annals of the Rheumatic Diseases, 29, 509-515.

Stuhlastz, H. W. (1973). The relation of glycosaminoglycans and glycoproteins to collagen and non-collagenous protein in pressure and non-pressure areas of the hip-joint cartilage of the femur. Connective Tissue and Ageing, p. 149. Edited by H. G. Vogel. Excerpta Medica: Amsterdam.

Venn, M. F. (1978). Variation of chemical composition with age in human femoral head cartilage. Annals of the Rheumatic Diseases, 37, 168-174. 